\title{
Incomplete Exchange Rate Pass-Through and Simple Monetary Policy Rules
}

\author{
Malin Adolfson* \\ Stockholm School of Economics, Department of Economics, P.O. Box 6501, S-113 83 Stockholm
}

SSE/EFI Working Paper Series in Economics and Finance

No. 478

October 2001

\begin{abstract}
The performance of various monetary rules is investigated in an open economy with incomplete exchange rate pass-through. Implementing monetary policy through an exchange-rate augmented policy rule does not improve social welfare compared to using an optimized Taylor rule, irrespective of the degree of pass-through. However, an indirect exchange rate response, through a policy reaction to Consumer Price Index (CPI) inflation rather than to domestic inflation, is welfare enhancing in all pass-through cases. This result is moreover independent of whether society values domestic or CPI inflation stabilization. The only case where a direct real exchange rate response is slightly welfare improving occurs when the other reaction coefficients, on inflation and output, are sub-optimal.
\end{abstract}

Keywords: Exchange rate pass-through, monetary policy, simple policy rules, small open economy, Taylor rule

$J E L:$ E52, E58, F41

*Tel.: +468 73696 47,fax: +4683132 07,e-mail: malin.adolfson@hhs.se

I am grateful to Paul Söderlind, Ulf Söderström, Marianne Nessén, and Anders Vredin for comments and valuable discussions. I would also like to thank Paul for providing extraordinary GAUSS routines. Financial support from Jan Wallander's Foundation is gratefully acknowledged. 


\section{Introduction}

In a small open economy, where the exchange rate influences inflation and output via import prices and relative prices, the exchange rate will also transmit monetary policy, in addition to the traditional (i.e. closed economy) interest rate channel. If the exchange rate contains information about, for example, inflationary impulses, the policy maker might improve social welfare (in the conduct of monetary policy) by extending her simple policy rule to include a direct feedback from the exchange rate. The reason for this is multifaceted; first, augmenting the policy rule with an exchange-rate term does, to some extent, internalize the 'total' effects interest rate adjustments have on the economy, since movements in the interest rate also influence the exchange rate. Hence, there might be an informational advantage to such a policy rule, measuring the overall position of the policy (see e.g. Ball (1999)). Second, by including a lagged exchange-rate term in the policy rule, the central banker could possibly filter out transitory effects of exchange rate fluctuations on inflation, when adjusting the interest rate (Ball (2000)). In this case, a purchasing power parity-adjusted measure of inflation will be targeted, which might imply less volatility in the interest rate. This, in turn, circumvents excessive variations in output. Third, a policy rule including the exchange rate might be less restrictive in that it incorporates a direct reaction to the inflationary impulse, or shock, rather than only responding to the result of the exchange rate movement (i.e. changes in inflation and output). Consequently, this implies a possibility to directly adjust the interest rate and offset the exchange rate effects on, for example, spending.

Prior literature analyzing open economies and simple policy rules has explored a broad set of exchange-rate augmented policy rules, without attaining a complete consensus of whether it is beneficial (or not) to include some feedback from an exchange rate variable in the central bank's instrument rule. ${ }^{1}$ The purpose of this paper is to study and describe the optimal policy rule, where optimality is measured in terms of social welfare, in an open economy with

\footnotetext{
${ }^{1}$ Among the previously evaluated policies are, for example, rules incorporating the real exchange rate, the current and lagged real exchange rate, or the change in the nominal exchange rate. Ball (1999) and Ball (2000) use a backward-looking model, concluding that the optimal simple rule should encompass a real exchange-rate term and that 'long-run' inflation should be targeted (i.e. excluding transitory effects of the exchange rate). For the use of the exchange rate-augmented policy rules in forward-looking models, see e.g. Batini et al. (2001), Leitemo and Söderström (2001), McCallum and Nelson (1999), and Taylor (2001). The majority of these authors find that, in terms of welfare, the performance of different simple rules is only marginally (if at all) improved by including a direct feedback from some exchange-rate term. In contrast, Monacelli (1999), and Weerapana (2000) both show that the welfare improvement of using a policy rule incorporating an exchange-rate term is somewhat more substantial, at least when the exchange rate pass-through is incomplete or, as in the latter case, when the volatility of exchange rate shocks is large. In addition, Cecchetti et al. (2000) find that a response to the real exchange rate is beneficial, also when using inflation forecast based rules for implementing policy.
} 
incomplete exchange rate pass-through. In particular, the importance of the degree of passthrough is investigated. If the policy maker implements inflation targeting through an instrument rule, should the nominal or real exchange rate be incorporated into this rule, and is this affected by whether the exchange rate pass-through is incomplete? The analysis is pursued in a simple aggregate demand-aggregate supply model, where incomplete exchange rate passthrough is included in the model via nominal import price rigidities. This, consequently, implies short-run deviations from the law of one price.

The main results obtained in the paper are that; $i$ ) the social welfare improvement of incorporating an exchange-rate term in the fully optimized policy rule is practically zero, irrespective of the degree of pass-through. However, adding a real exchange rate response to the non-optimized Taylor rule does enhance social welfare somewhat, since it reduces the suboptimality of the overall policy response (i.e. the resulting interest rate adjustment). ii) An indirect exchange rate response, attained through a policy reaction to CPI inflation rather than domestic inflation, is welfare enhancing. This result holds independent of the degree of passthrough, and it is not contingent upon society's preferences for either CPI inflation-stabilization or domestic inflation-stabilization.

In Section 2, the economic model as well as three different exchange-rate augmented policy rules are presented. These simple rules incorporate either a nominal, or a real, exchange-rate term, in order to take advantage of any latent exchange rate effects, as discussed above. Section 3 contains the optimal policy reactions and the stabilization outcome of the different policy rules in terms of social welfare. Robustness issues are described in Section 4, and lastly some conclusions are provided in Section 5.

\section{Model}

The model is an open economy aggregate supply-aggregate demand model, adjusted for shortrun incomplete exchange rate pass-through, and based on the agents' optimizing behaviour. The consumers attain utility from consumption of domestic as well as import goods, supplied by a domestic and a foreign producer, respectively. Both producers sell their goods to the domestic and the foreign market, setting prices optimally under some Rotemberg (1982) price stickiness. $^{2}$

\footnotetext{
${ }^{2}$ For a more thorough discussion of the model and its underlying microfoundations, see Adolfson (2001a).
} 
The economy of primary interest (called domestic) consists of three (log-linearized) equations determining inflation, output, and expected exchange rate changes: ${ }^{3}$

$$
\begin{aligned}
& \pi_{t}=\left(1-\kappa_{M}\right) \pi_{t}^{D}+\kappa_{M} \pi_{t}^{M} \\
&=\alpha_{\pi} \mathrm{E}_{\mathrm{t}} \pi_{t+1}+\alpha_{y} y_{t}+\alpha_{q}\left(p_{t}^{M}-p_{t}^{D}\right)+\alpha_{p}\left(p_{t}^{*}+e_{t}-p_{t}^{M}\right)+\varepsilon_{t}^{\pi}, \\
& y_{t}=\mathrm{E}_{\mathrm{t}} y_{t+1}-\beta_{q} \mathrm{E}_{\mathrm{t}}\left(\pi_{t+1}^{M}-\pi_{t+1}^{D}\right)-\beta_{i}\left(i_{t}-\mathrm{E}_{\mathrm{t}} \pi_{t+1}\right)+\beta_{e}\left(\mathrm{E}_{\mathrm{t}} \pi_{t+1}^{D}-\left(\mathrm{E}_{\mathrm{t}} e_{t+1}-e_{t}\right)-\mathrm{E}_{\mathrm{t}} \pi_{t+1}^{*}\right) \\
&-\beta_{y}^{*}\left(\mathrm{E}_{\mathrm{t}} y_{t+1}^{*}-y_{t}^{*}\right)+\varepsilon_{t}^{y}, \\
& i_{t}-i_{t}^{*}=\mathrm{E}_{\mathrm{t}} e_{t+1}-e_{t}+\varepsilon_{t}^{\phi} .
\end{aligned}
$$

Equation (1) is an aggregate supply relation obtained from the aggregate price index underlying the constant elasticity of substitution (CES) function for consumption, and the producers' optimal price setting, assuming nominal rigidities. Aggregate inflation (i.e. consumer price inflation) is a convex combination of inflation of domestically produced goods $\left(\pi_{t}^{D}\right)$ and imported inflation $\left(\pi_{t}^{M}\right) . y_{t}$ denotes aggregate output, $\left(p_{t}^{M}-p_{t}^{D}\right)$ is the relative price of imports, describing the inverse of the terms of trade (i.e. a particular real exchange rate measure), which turns up because of imported intermediate inputs, and $e_{t}$ is the nominal exchange rate (domestic currency per unit of foreign currency). Deviations from the law of one price arise due to the nominal import price stickiness and are captured by the term $\left(p_{t}^{*}+e_{t}-p_{t}^{M}\right)$, where the price stickiness parameter $\alpha_{p}$ governs the degree of exchange rate pass-through. A less complete, or smaller, short-run pass-through occurs in the model by assigning a greater price rigidity, that is, a smaller $\alpha_{p}$. Finally, $\varepsilon_{t}^{\pi}$ encapsulates a disturbance to domestic supply (or to be exact, a domestic cost push shock that does not directly affect aggregate output) following the autoregressive process, $\varepsilon_{t+1}^{\pi}=\tau_{\pi} \varepsilon_{t}^{\pi}+u_{t+1}^{\pi}$, where $u_{t+1}^{\pi}$ is an iid disturbance with zero mean and variance $\sigma_{\pi}^{2}$.

Equation (2) is an aggregate demand relation derived from a standard Euler equation of the households' intertemporal consumption decision, using the demand relations from the underlying CES aggregator. Domestic demand shocks (e.g. originating from preference shifts)

\footnotetext{
${ }^{3}$ The notation is as follows; lower case letters denote logarithmic values (deviations from steady-state), a superscript indicates whether domestic or import goods are considered, and an asterisk represents foreign variables. A price characterized with an asterisk consequently denotes the foreign currency price. Lastly, $\mathrm{E}_{\mathrm{t}}$ denotes rational expectations as of period $t$.
} 
are captured in $\varepsilon_{t}^{y}$ that follows, $\varepsilon_{t+1}^{y}=\tau_{y} \varepsilon_{t}^{y}+u_{t+1}^{y}$, with $u_{t+1}^{y}$ as an iid disturbance term with zero mean and variance $\sigma_{y}^{2}$. This output relation differs from its full pass-through equivalence because of the (short-run) deviations from the law of one price, which makes the relative price of imports $\left(p_{t}^{M}-p_{t}^{D}\right)$ and the relative price of exports $\left(p_{t}^{D}-e_{t}-p_{t}^{*}\right)$ diverge. ${ }^{4}$ The internal relative price (of imports) appears through its effect on domestic consumers' demand, while the external relative price (of exports) shows up due to the foreign consumers' demand for domestic goods.

Equation (3) is a modified uncovered interest rate parity condition derived from the consumers' optimal holdings of domestic and foreign bonds, assuming an added risk premium $\left(\varepsilon_{t}^{\phi}\right)$ to the foreign bond prices. The risk premium is a 'pure' exchange rate disturbance capturing autonomous shocks to expectations about the future exchange rate. ${ }^{5}$ The risk premium follows the $\operatorname{AR}(1)$ process, $\varepsilon_{t+1}^{\phi}=\tau_{\phi} \varepsilon_{t}^{\phi}+u_{t+1}^{\phi}$, where $u_{t}^{\phi}$ is an iid disturbance with zero mean and variance $\sigma_{\phi}^{2}$.

The domestic economy is small in the sense that conditions in the foreign economy are exogenously given. The foreign inflation and output relations are assumed to consist of persistent $\mathrm{AR}(1)$ processes, while the foreign monetary policy is presumed to be implemented through a simple Taylor rule with some interest rate persistence added, as suggested by empirical evidence (see, e.g., Clarida et al. (1998)):

$$
\begin{aligned}
& y_{t+1}^{*}=\rho_{y}^{*} y_{t}^{*}+u_{t+1}^{y^{*}}, \\
& \pi_{t+1}^{*}=\rho_{\pi}^{*} \pi_{t}^{*}+u_{t+1}^{\pi^{*}}, \\
& i_{t+1}^{*}=\left(1-\rho_{i}^{*}\right)\left(b_{\pi}^{*} \pi_{t+1}^{*}+b_{y}^{*} y_{t+1}^{*}\right)+\rho_{i}^{*} i_{t}^{*}+u_{t+1}^{i *},
\end{aligned}
$$

\footnotetext{
${ }^{4}$ The relative price change turns up in equation (2) because it affects the intertemporal consumption decision, while the relative price level affects the intratemporal allocation between consumption of imports and domestic goods. Note, however, that the difference terms disappear when solving equation (2) forward.

${ }^{5}$ Other independent exchange rate disturbances are hard to distinguish since the exchange rate is affected by anything influencing the interest rate differential in equation (3). This implies that any domestic or foreign shock creating a policy reaction also generates an exchange rate movement.
} 
where $\rho_{y}^{*}, \rho_{\pi}^{*}, \rho_{i}^{*}$ are non-negative coefficients less than unity, and $u_{t+1}^{y^{*}}, u_{t+1}^{\pi^{*}}, u_{t+1}^{i^{*}}$ are iid disturbances with zero mean and variance $\sigma_{y^{*}}^{2}, \sigma_{\pi^{*}}^{2}$ and $\sigma_{i^{*}}^{2}$, respectively. ${ }^{6,7}$

In brief, the distinguishing features of the model are consequently departures from full passthrough, in both supply and demand relations, and entirely forward-looking agents.

\subsection{Simple policy rules and social preferences}

Monetary policy is assumed to be implemented through commitment to a 'simple' instrument rule, as suggested by Taylor (1993), where the short-run interest rate is the policy maker's instrument. The policy maker is assumed to follow such a sub-optimal policy rule, rather than explicitly deriving her reaction function from a policy objective function, due to reasons of, for example, transparency (credibility and monitorability). ${ }^{8}$ It might be easier for the central banker to explain the conduct of monetary policy when following a simple rule, as well as making it more straightforward for the public to evaluate the policy maker's performance. In addition, there is some notion in the literature that the outcome of simple rules are robust across different models (see, e.g., Levin et al. (1999)). That is, even if there is uncertainty about the underlying economic relations, a simple rule will generate the same response to, for example, an inflationary impulse, irrespective of the theoretical model used. In contrast, reaction functions directly derived from the policy maker's objective function are more complex and highly contingent upon the particular choice of model representation. Nevertheless, recall that the use of simple rules was initiated as the outcome of an empirical exercise for a closed economy, and lacks major theoretical foundations. Which policy rule to be followed in an open economy is therefore still a very open question. As mentioned in the Introduction, there have been suggestions that the open economy-policy rule ought to incorporate the exchange rate, so as to exploit the exchange rate's transmission of monetary policy (see, e.g., Ball (1999)). The following set of different policy rules is therefore simply postulated, and evaluated:

\footnotetext{
${ }^{6}$ The shocks to foreign output and inflation are assumed to be uncorrelated. Note, however, that the subsequent results are not affected by changing this assumption so that $u_{t+1}^{y^{*}}$ and $u_{t+1}^{\pi^{*}}$ are correlated.

${ }^{7}$ The monetary policy in one country can probably be described by a simple Taylor rule. However, using a single rule to represent the 'rest of the world's' cohesive policy is less plausible, and therefore requires a disturbance term. $u_{t+1}^{i^{*}}$ captures foreign interest rate changes, or monetary policy changes, that are not encapsulated by the Taylor rule.

${ }^{8}$ Adolfson (2001b) discusses the somewhat related issue of what the optimal discretionary policy should be in an open economy with incomplete exchange rate pass-through.
} 


$$
\begin{aligned}
& i_{t}=(1-\rho)\left(b_{\pi} \pi_{t}+b_{y} y_{t}\right)+\rho i_{t-1}, \\
& i_{t}=(1-\rho)\left(b_{\pi} \pi_{t}+b_{y} y_{t}+b_{\Delta e}\left(e_{t}-e_{t-1}\right)\right)+\rho i_{t-1}, \\
& i_{t}=(1-\rho)\left(b_{\pi} \pi_{t}+b_{y} y_{t}+b_{(p m-p d)}\left(p_{t}^{M}-p_{t}^{D}\right)\right)+\rho i_{t-1}, \\
& i_{t}=(1-\rho)\left(b_{\pi} \pi_{t}+b_{y} y_{t}+b_{\left(p^{*}+e-p\right)}\left(p_{t}^{*}+e_{t}-p_{t}\right)\right)+\rho i_{t-1},
\end{aligned}
$$

where $b_{\pi}, b_{y}, b_{\Delta e}, b_{(p m-p d)}$ and $b_{\left(p^{*+e-p)}\right.}$ are the policy maker's reaction coefficients, and $\rho$ is the degree of interest rate persistence. The policy maker sets the interest rate as a linear function of the lagged interest rate and the deviations of CPI inflation and output (and possibly the exchange rate) from their zero targets. ${ }^{9}$ Equation (7a), setting $\rho=0$, is the simple rule suggested by Taylor (1993), while Clarida et al. (2000) advocate that the persistence parameter, $\rho$, is typically $0.8-0.9$ for this simple rule to be consistent with the empirical evidence. Three other rule specifications incorporate the exchange rate in some form. Equation (7b) states that monetary policy should react to changes in the nominal exchange rate. The reason for this is that the nominal exchange rate difference possibly indicates a direct inflationary impulse, which can be offset by an explicit policy response to the change in the exchange rate. Recall, though, that such a difference might only reflect temporary fluctuations in the exchange rate. ${ }^{10}$ The real exchange rate may also mirror temporary fluctuations, but with sticky prices and incomplete pass-through, that possibility might be smaller, since the real exchange rate is a relative price. Consequently, equation (7c) incorporates the relative price of imports into the policy rule, while equation (7d) uses a different definition of the real exchange rate, namely the relative consumer price. Hence, the latter two rules both adjust the interest rate to a particular real exchange rate specification, but because of incomplete pass-through, the two characterizations of the real exchange rate are not equivalent. $\left(p^{M}-p^{D}\right)$ in equation (7c) captures the terms of trade, while $\left(p^{*}+e-p\right)$ in equation (7d) captures deviations from purchasing power parity (PPP) between the foreign and domestic economy. Note also that the degree of pass-through influences these two variables differently, in the face of, for instance, a risk premium shock. As pass-through

\footnotetext{
${ }^{9}$ Note that equations (7a)-(7d) are not reaction functions in an exact sense, since inflation, output and the exchangerate terms are not predetermined state variables. Rather, these equations represent equilibrium relations from which the system's dynamics can be backed out, that, in turn, relate the forward-looking variables to the predetermined variables. Moreover, note that the subsequent results are qualitatively robust to changing the policy rule so that, in contrast, the interest rate only depends on lagged variables.

${ }^{10}$ Note that there are no transmission lags of monetary policy here, why the policy maker can respond to all disturbances, temporary as well as permanent, as long as they turn up in any of the target variables. However, if interest rate volatility is detrimental to social welfare for some reason, the policy maker probably wants to disregard transitory exchange rate movements.
} 
decreases, the deviations from purchasing power parity becomes larger (because of larger departures from the law of one price), while the terms of trade are expected to become more stable.

The above suggested policy rules are evaluated in terms of a social loss function. Social preferences are assumed to follow a standard objective function with quadratic deviations of CPI inflation and output from their constant target levels (here normalized to zero for simplicity):

$$
\begin{array}{ll}
\min _{\left\{i_{i+j}\right\}_{j=0}^{\infty}} & \mathrm{E}_{\mathrm{t}} \sum_{j=0}^{\infty} \beta^{j} L_{t+j}^{S} \\
\text { where } & L_{t}^{S}=\left[\pi_{t}^{2}+\lambda^{S} y_{t}^{2}\right],
\end{array}
$$

where $0<\beta<1$ is a discount factor, and $\lambda^{S}$ is the relative weight society puts on output stabilization. ${ }^{11}$ To minimize the social loss function and find the optimal simple rule, the model (equations (1)-(6)) is expressed in state-space form (see Appendix A), implying that the minimization in equation (8) can be stated as a linear-quadratic problem. The policy maker is assumed to be able to commit to either of the simple policy rules in equation (7). As the discount factor, $\beta$, approaches unity, it can be shown that the limit of the scaled intertemporal loss function can be expressed as the unconditional mean of the period loss function (see Rudebusch and Svensson (1999)):

$$
\mathrm{E}\left[L_{t}^{S}\right]=\operatorname{Var}\left(\pi_{t}\right)+\lambda^{S} \operatorname{Var}\left(y_{t}\right)
$$

The loss function in equation (9) is used to assess which rule in equation (7) provides a superior stabilization of the economy, as well as for optimizing the reaction coefficients in each policy rule. Equation (9) is estimated using asymptotic variances that can be obtained from the solution (or transition matrix) of the model, which are both described in Appendix A. The model is solved using numerical methods, for example described in Söderlind (1999), why it needs to be

\footnotetext{
${ }^{11}$ In a closed economy, Woodford (2001) shows that this objective function represents a second-order Taylor approximation of the expected utility for the representative household, making it a reasonable welfare measure for monetary policy. This loss function is also appropriate in an open economy with incomplete pass-through, since the relative price distortion that occurs due to sticky domestic prices and rigid import prices can be mitigated with stable CPI inflation. Stabilization of CPI inflation consequently reduces the uncertainty about future real consumption, which is welfare improving for the risk averse consumers. For a detailed discussion of the open economy-social objectives and their pass-through aspects, see Section 3.4. below.
} 
parameterized. The parameter values shown in Table 1 are based on underlying deep parameters, which are chosen along the lines of prior literature.

Table 1: Parameterization

\begin{tabular}{|c|c|c|c|c|c|c|}
\hline \hline $\begin{array}{c}\text { Social } \\
\text { preferences }\end{array}$ & $\begin{array}{c}\text { Benchmark } \\
\text { policy rule }\end{array}$ & $\begin{array}{c}\text { Supply } \\
\text { relation }\end{array}$ & $\begin{array}{c}\text { Demand } \\
\text { relation }\end{array}$ & $\begin{array}{c}\text { Foreign } \\
\text { economy }\end{array}$ & $\begin{array}{c}\text { Shock } \\
\text { persistence }\end{array}$ & $\begin{array}{c}\text { Shock } \\
\text { variance }\end{array}$ \\
\hline \multirow{3}{*}{$\beta=0.99$} & $b_{\pi}=1.5$ & $\kappa_{M}=0.3$ & $\beta_{q}=1.26$ & $\rho_{y}{ }^{*}=0.8$ & $\tau_{\pi}=0.8$ & $\sigma_{\pi}^{2}=0.4$ \\
$\lambda^{S}=0.5$ & $b_{y}=0.5$ & $\alpha_{\pi}=0.99$ & $\beta_{i}=0.35$ & $\rho_{\pi}{ }^{*}=0.8$ & $\tau_{y}=0.8$ & $\sigma_{y}^{2}=0.6$ \\
& $\rho=0.8$ & $\alpha_{y}=0.056$ & $\beta_{e}=1.8$ & $\rho_{i}{ }^{*}=0.8$ & $\tau_{\phi}=0.8$ & $\sigma_{\phi}^{2}=0.8$ \\
& & $\alpha_{q}=0.007$ & $\beta_{y}{ }^{*}=0.27$ & $b_{y}{ }^{*}=0.5$ & & $\sigma_{\pi^{*}}^{2}=0.05$ \\
& & $\alpha_{p}=\{30,0.6,0.15,0.03\}$ & & $b_{\pi}{ }^{*}=1.5$ & & $\sigma_{y^{*}}^{2}=0.1$ \\
& & & & & & $\sigma_{i^{*}}^{2}=0.01$ \\
\hline \hline
\end{tabular}

The parameter of main interest for the twist of this paper, is the exchange rate pass-through related parameter $\left(\alpha_{p}\right)$ governing the level of adjustment costs, and thereby also the degree of pass-through. It is chosen in order to cover four different rates of exchange rate pass-through; a full-pass through case (99\%), and three intermediate cases of incomplete pass-through (66\%, $33 \%$, and $9 \%) .^{12}$ The rest of the parameter-setup is fairly standard, for example capturing rather moderate import and export shares (30\% of aggregate consumption and aggregate demand, respectively), a markup of $20 \%$ arising from a substitution elasticity between domestic and imported goods equal to 6 , an intertemporal substitution elasticity of 0.5 , and rather persistent shocks where the AR(1)-component is $0.8 .^{13}$ Further, the variances of the disturbance terms are more or less taken from a structural vector auto-regression on Norwegian data (see Leitemo and Røisland (2000)). The benchmark policy rule takes on the standard reaction coefficients of 1.5 and 0.5 , on inflation and output, respectively, as well as imposing some interest rate persistence; 0.8 .

\footnotetext{
${ }^{12}$ For empirical basis of incomplete exchange rate pass-through in small open economies, see e.g. Adolfson (1997), and Naug and Nymoen (1999).

${ }^{13}$ See Adolfson (2001a) for an exact mapping between the parameters shown in Table 1 and these deep parameters.
} 


\section{Results}

\subsection{Standard (non-optimized) reaction coefficients}

Figure 1 illustrates the social loss from implementing monetary policy through the three exchange-rate augmented policy rules, varying the degree of exchange rate reactions. The reaction coefficients on inflation, output and the lagged interest rate are the ones suggested by Taylor (1993), and Clarida et al. (2000), while the response coefficient on the respective exchange-rate term varies between -1 and 1 . Inclusion of an exchange rate reaction, through any of the three rules, seems to reduce social loss somewhat. Moreover, the optimal degrees of exchange rate response appear to be dependent on the degree of pass-through (cf. Figures 1a and $1 d)$.

This is also shown in Table 2, which displays the optimized exchange rate responses and the resulting social loss. The exchange rate reaction, as well as the welfare enhancement, is increasing in the degree of pass-through. Thus, when pass-through is high, the exchange rate plays a more important role in predicting inflationary impulses and consequently, the welfare enhancement of including an exchange-rate term is larger. However, the results indicate that the welfare improvement of incorporating either the nominal exchange rate change, the terms of trade, or deviations from PPP, is moderate (i.e. 0-4\% enhancement). Note though that the rules incorporating the real exchange rate perform somewhat better in terms of social welfare, than the rule including the nominal exchange rate change. The largest welfare gain appears to be occurring when the policy maker responds to deviations from PPP. One reason could be that this term better captures the distortion that occurs due to the price stickiness in the model, namely departures from the law of one price. Recall that low pass-through implies less influence of foreign disturbances. On the other hand, this lower pass-through is induced by larger nominal rigidity. Consequently, the policy maker faces a trade-off between the lower effects of exchange rate fluctuations and the larger deviations from the flexible price outcome. 
Table 2: Social loss $\left(L^{S}\right)$ and optimized exchange rate reaction coefficients $\left(\hat{b}_{\Delta e}, \hat{b}_{(p m-p d)}, \hat{b}_{\left(p^{*}+e-p\right)}\right)$, using standard reaction coefficients on $\left(b_{\pi}, b_{y}, \rho\right)$

\begin{tabular}{|c|c|c|c|c|c|c|c|}
\hline \multirow[b]{2}{*}{ Pass-through } & \multirow{2}{*}{$\begin{array}{c}\text { equation (7a) } \\
\qquad L^{S} \\
\end{array}$} & \multicolumn{4}{|c|}{$b_{\pi}=1.5, b_{y}=0.5, \rho=0.8$} & \multicolumn{2}{|c|}{ equation (7d) } \\
\hline & & $\hat{b}_{\Delta e}$ & Rel. $L^{S}$ & $\hat{b}_{(p m-p d)}$ & Rel. $L^{S}$ & $\hat{b}_{\left(p^{*}+e-p\right)}$ & Rel. $L^{S}$ \\
\hline 0.99 & 1 & 0.3 & 0.98 & 0.4 & 0.964 & 0.6 & 0.963 \\
\hline 0.66 & 1 & 0.2 & 0.992 & 0.3 & 0.982 & 0.6 & 0.96 \\
\hline 0.33 & 1 & 0.1 & 0.997 & 0.2 & 0.994 & 0.6 & 0.96 \\
\hline 0.09 & 1 & 0 & 1.0 & 0 & 1.0 & 0.4 & 0.971 \\
\hline
\end{tabular}

Note: For some parameter values in the grid search (over -1 to 1 with step 0.1 ), the specified decision rule does not stabilize the system (i.e. there is no unique solution).

\subsection{Optimized reaction coefficients}

Note that the standard reaction coefficients (i.e. $b_{\pi}=1.5, b_{y}=0.5$, and $\rho=0.8$ ) need not be optimal for the particular model used here, as they are derived from the monetary policy observed in a closed economy (see Taylor (1993)). If the policy rule is excessively simple, or sub-optimal, the inclusion of any additional state variable will probably yield an improvement of the rule. The welfare enhancement recorded in Table 2 could, consequently, originate from the fact that the exchange-rate augmented policy rules simply respond to more variables than a rule without the exchange rate. However, optimizing the other reactions (on inflation, output, and the interest rate persistence) will reduce the sub-optimality of the simple rule, which partly mitigates this problem. Therefore all policy reactions are optimized, using a grid search over a range of values.

Table 3a displays the optimized reaction coefficients on inflation, output, and the interest rate persistence for the policy rule without the exchange rate (i.e. equation (7a)). Note that the optimal interest rate persistence is very high, for all pass-through cases, which is also consistent with the monetary policy conduct actually observed (see Clarida et al. (1998)). Moreover, the response coefficients for the optimized rule do not at all resemble the policy rule suggested by Taylor (1993). In contrast to Taylor's rule, the optimized responses to both inflation and output are much larger here, while their relative difference appears to be less sizeable, irrespective of the degree of pass-through. However, that the optimized policy rule induces a more vigorous policy than what is typically found empirically is not specific to the setting used here, but appears to be a common result in many models (see e.g. Batini et al. (2001), and Rudebusch and 
Svensson (1999)). ${ }^{14}$ Note also that the inflation response appears to be slightly larger in the full pass-through case, compared to the two intermediate cases of incomplete pass-through. Since the exchange rate channel in the full pass-through case transmits shocks to a greater extent, this requires a more forceful policy reaction. The differences are rather small, however, and moreover, dependent on which disturbances enter the economy (see Figure 3 for impulse responses).

Figure 2 describes the social loss resulting from the optimized rule, adding different degrees of exchange rate reactions. The welfare enhancement of following these exchange-rate augmented rules is, if any, very small. As a result of optimizing all reaction coefficients, the role of the exchange rate in the policy rule thus appears to be less notable, compared to the findings above.

Table $3 b$ shows the optimized response coefficients on the different exchange-rate terms, as well as the relative social loss. The responses on inflation, output, and the lagged interest rate are optimized separately, in order to scrutinize the marginal value of incorporating the exchange rate. ${ }^{15}$ None of the augmented rules appears to significantly reduce the social loss, even if most of the optimized exchange rate reactions are different from zero. Although small, the optimized reactions on the nominal exchange rate change and the terms of trade are increasing in the degree of pass-through, while the response to deviations from PPP does not appear to increase monotonically with larger pass-through. However, the welfare improvement of incorporating the nominal exchange rate change, or one of the two real exchange-rate terms, is practically zero in most pass-through cases (i.e. less than $0.1 \%$ ).

The exchange rate channel of transmitting monetary policy can perhaps explain the negative reaction coefficients that turn up in some cases. It follows from equation (3) that a positive domestic-foreign interest rate differential implies an expected future depreciation, which, in turn, induces an inflationary impulse that raises the interest rate even further. A negative policy response to the exchange rate mitigates the interest rate adjustment when the exchange rate depreciates. All policy effects are thus internalized, which eases this goal conflict. Note also that the volatility in the endogenously determined exchange rate is decreasing in the degree of pass-

\footnotetext{
${ }^{14}$ For empirical estimates of the Taylor rule, see, e.g., Clarida et al. (2000) for the US, and Gerlach and Schnabel (2000) for the EMU countries.

${ }^{15}$ Another way of measuring the additive value of the exchange rate is to simultaneously optimize all reaction coefficients, and subsequently measure the welfare loss when excluding the exchange rate. Leaving out the exchange rate in that case does, however, present a different, and sub-optimal, relation between the inflation and output reactions why the marginal loss of excluding the exchange rate is more difficult to assess.
} 
through. ${ }^{16}$ Low pass-through consequently induces larger exchange rate variability, which causes a more negative policy reaction to the exchange rate. However, the overall interest rate response to a depreciation is still positive, since the policy reaction to CPI inflation raises the interest rate.

Table 3a: Social loss $\left(L^{S}\right)$ and optimized reaction coefficients $\left(\hat{b}_{\pi}, \hat{b}_{y}, \hat{\rho}\right)$; equation (7a)

\begin{tabular}{|l|c|c|c|}
\hline \hline \multirow{2}{*}{ Pass-through } & \multicolumn{2}{|c|}{$\begin{array}{c}\text { equation (7a) } \hat{\rho} \\
\hat{b}_{y}\end{array}$} \\
\hline \multirow{3}{*}{0.99} & $\hat{b}_{\pi}$ & 2.8 & $\hat{\rho}$ \\
0.66 & 3.7 & 2.6 & 0.8 \\
0.33 & 3.5 & 2.6 & 0.8 \\
0.09 & 3.4 & 3.2 & 0.8 \\
\hline \hline
\end{tabular}

Table 3b: Social loss $\left(L^{S}\right)$ and optimized exchange rate reaction coefficients $\left(\hat{b}_{\Delta e}, \hat{b}_{(p m-p d)}, \hat{b}_{\left(p^{*}+e-p\right)}\right)$, using optimized reaction coefficients $\left(\hat{b}_{\pi}, \hat{b}_{y}, \hat{\rho}\right)$

\begin{tabular}{|l|c|cc|cc|cc|}
\hline \hline & \multicolumn{9}{|c|}{$\hat{b}_{\pi}, \hat{b}_{y}, \hat{\rho}$ optimized (see Table 3a) } \\
& \multicolumn{9}{|c|}{ equation (7b) } & \multicolumn{2}{c|}{ equation (7c) } \\
Pass-through & equation (7a) & $\hat{b}_{\Delta e}$ & Rel. $L^{S}$ & $\hat{b}_{(p m-p d)}$ & Rel. $L^{S}$ & $\hat{b}_{\left(p^{*}+e-p\right)}$ & Rel. $L^{S}$ \\
\hline & $L^{S}$ & & & & & & \\
0.99 & 1 & 0.1 & 0.9995 & 0.1 & 0.9998 & 0.2 & 0.9998 \\
0.66 & 1 & 0.1 & 0.9999 & 0 & 1.0 & 0.1 & 0.9998 \\
0.33 & 1 & 0 & 1.0 & -0.2 & 0.999 & 0.2 & 0.9995 \\
0.09 & 1 & -0.1 & 0.999 & -0.6 & 0.988 & 0.9 & 0.989 \\
\hline \hline
\end{tabular}

Note: $b_{\pi}, b_{y}, \rho$ are optimized separately (see Table 3a) in order to reflect the marginal advantage of incorporating an exchange-rate term. The optimized exchange rate responses are established by a grid search over -1 to 1 , with step 0.1 .

Altogether, the results indicate that social welfare might possibly be improved by adding an exchange-rate term to the non-optimized policy rule, but not to the optimized policy rule. These contrasting findings are simply explained from the other optimized responses. The optimized responses to inflation and output are larger than the ones suggested by Taylor (1993), which implies a more aggressive interest rate adjustment. Inclusion of an exchange-rate term (i.e. a

\footnotetext{
${ }^{16}$ In this model, lower pass-through is induced by larger structural price stickiness, why the required relative price adjustment is accomplished through larger exchange rate fluctuations (see Table A1 in the Appendix).
} 
positive exchange rate reaction) precisely implies a larger interest rate response to inflationary impulses reflected in the exchange rate, which thus results in an implicit development towards the optimized policy rule without the exchange rate.

\subsection{Responding to domestic inflation}

Another reason why the exchange-rate augmented rules are only marginally, if at all, welfare improving, might be that the instrument rule already contains an implicit reaction to the exchange rate, realized through the response to CPI inflation. Consequently, Taylor (2001) suggests that the CPI inflation-interest rate rule includes a sufficient exchange rate response. If, in contrast, the policy maker adjusts the interest rate to domestic inflation $\left(\pi^{D}\right)$, most of the direct exchange rate impact is filtered out. ${ }^{17}$ Hence, if the exchange rate does play an explicit role in the policy rule, its emphasis ought to be higher when responding to domestic inflation compared to reacting to CPI inflation. To test this hypothesis, the exchange-rate augmented rules are therefore analyzed using domestic inflation as a reaction variable.

Table 4 presents the social loss and the optimized response coefficients, when the policy rule consists of domestic inflation, output, the interest rate, and the various exchange-rate terms. Comparing the social loss under the domestic inflation rules and the CPI inflation rules indicates that implementing monetary policy through a rule based on CPI inflation yields a better outcome in terms of social welfare. Furthermore, the results in Tables 3 and 4 show that the inclusion of any exchange-rate term is relatively more welfare enhancing under the domestic inflation rule than under the CPI inflation rule, although the differences are very small. This reflects that some of the exchange rate reaction, in fact, is inherent in the CPI inflation response, as discussed above. Still, there is no strong indication that a direct exchange rate response should be added to the optimized policy rule.

\footnotetext{
${ }^{17}$ Note, however, that the exchange rate still indirectly affects domestic inflation in this model, through imported inputs and expenditure switching effects via aggregate demand.
} 
Table 4: Relative social loss and optimized reaction coefficients, policy reaction to domestic inflation $\left(\pi_{t}^{D}\right)$

\begin{tabular}{|c|c|c|c|c|c|c|c|c|c|c|}
\hline \multirow{2}{*}{$\begin{array}{l}\text { Pass- } \\
\text { through }\end{array}$} & \multirow[b]{2}{*}{$\hat{b}_{\pi}$} & \multicolumn{2}{|c|}{ equation $(7 a)$} & \multirow[b]{2}{*}{$L_{d}^{S} / L^{S}$} & \multicolumn{2}{|c|}{ equation (7b) } & \multicolumn{2}{|c|}{ equation $(7 c)$} & \multicolumn{2}{|c|}{ equation (7d) } \\
\hline & & $\hat{b}_{y}$ & $\hat{\rho}$ & & $\hat{b}_{\Delta e}$ & Rel. $L_{d}^{S}$ & $\hat{b}_{(p m-p d)}$ & Rel. $L_{d}^{S}$ & $\hat{b}_{\left(p^{*}+e-p\right)}$ & Rel. $L_{d}^{S}$ \\
\hline 0.99 & 3.8 & 3.0 & 0.8 & 1.013 & 0.2 & 0.999 & 0.3 & 0.999 & 0.4 & 0.999 \\
\hline 0.66 & 3.4 & 2.6 & 0.8 & 1.01 & 0.1 & 0.999 & 0.1 & 0.9998 & 0.4 & 0.999 \\
\hline 0.33 & 5.5 & 4.6 & 0.9 & 1.0 & 0.2 & 0.9996 & -0.1 & 0.9998 & 0.7 & 0.998 \\
\hline 0.09 & 3.3 & 2.9 & 0.8 & 1.024 & 0 & 1.0 & -0.7 & 0.982 & 1.0 & 0.98 \\
\hline
\end{tabular}

Note: $L_{d}^{S} / L^{S}$ denotes the relative loss compared to delegating equation (7a) based on CPI inflation. Rel. $L_{d}^{S}$ represents the relative loss between the respective exchange-rate augmented rule and equation (7a), based on domestic inflation (i.e. the loss reduction from exchange rate stabilization under domestic inflation targeting). $b_{\pi}, b_{y}, \rho$ are optimized separately in order to reflect the marginal advantage of incorporating an exchange-rate term.

\subsection{Social preferences}

As seen above, the question of whether to incorporate the exchange rate in the open economypolicy rule is related to the issue of what inflation measure the interest rate adjustment optimally is based on. This in turn might, however, be dependent on the society's particular welfare function. What is the correct objective function of an open economy? In a model with nominal rigidities, where prices do not adjust simultaneously, unnecessary variation in the relative price of goods (which, in turn, generates inflationary impulses) can be avoided by keeping the general price level stabilized (Woodford (2001)). The effects of nominal rigidities, that is the relative price distortions, can thereby be neutralized.

Some authors have argued that domestic inflation stabilization, rather than CPI inflation stabilization, characterizes the open economy-welfare criterion (see, for example, Sutherland (2001)). However, this reasoning builds on an assumption of full pass-through, such that import prices are in fact fully flexible. In this case, the distortion can be alleviated, and the flexible price outcome restored by stabilizing domestic inflation, to which the price stickiness pertains. On the other hand, in the model used here, both domestic and import prices are sticky, given incomplete pass-through. This implies that the distortion applies to both foreign and domestic producers, why general translates into the consumer price index to which the producers' relate 
their own price. Consequently, this suggests that CPI inflation should be stabilized when passthrough is incomplete. ${ }^{18}$

The results are in all pass-through cases, nonetheless, robust to evaluating the exchange-rate augmented rules from a social loss function including domestic inflation, that is $L_{t}^{D}=\operatorname{var}\left(\pi_{t}^{D}\right)+\lambda^{S} \operatorname{var}\left(y_{t}\right) \cdot{ }^{19}$ This is shown in Table 5, which displays the social loss $\left(L_{t}^{D}\right)$, and the optimized policy reactions, from policy rules based on either CPI inflation or domestic inflation. Note in particular that the implicit exchange rate reaction achieved through targeting CPI inflation is beneficial for the outcome, even if society values domestic inflation stabilization. The reason is that exchange rate volatility is lower under a policy rule based on CPI inflation (see Table 1 in the Appendix). This, in turn, is helpful also for stabilizing domestic inflation, since the latter is affected by exchange rate fluctuations through imported intermediate inputs. The lower exchange rate volatility improves the variance trade-off between domestic inflation and output, which thus is less considerable if the policy maker responds to CPI inflation (see Figure 4). Consequently, interest rate rules based on CPI inflation will be more welfare enhancing than the rules reacting to domestic inflation.

Table 5a: Social loss $\left(L^{D}=\operatorname{var}\left(\pi^{D}\right)+\lambda^{S} \operatorname{var}(y)\right)$, and optimized reaction coefficients, policy reaction to CPI inflation $\left(\pi_{t}\right)$

\begin{tabular}{|c|c|c|c|c|c|c|c|c|c|c|}
\hline \multirow{2}{*}{$\begin{array}{l}\text { Pass- } \\
\text { through }\end{array}$} & \multicolumn{4}{|c|}{ equation (7a) } & \multicolumn{2}{|c|}{ equation (7b) } & \multicolumn{2}{|c|}{ equation (7c) } & \multicolumn{2}{|c|}{ equation (7d) } \\
\hline & $\hat{b}_{\pi}$ & $\hat{b}_{y}$ & $\hat{\rho}$ & $L^{D}$ & $\hat{b}_{\Delta e}$ & Rel. $L^{D}$ & $\hat{b}_{(p m-p d)}$ & Rel. $L^{D}$ & $\hat{b}_{\left(p^{*}+e-p\right)}$ & Rel. $L^{D}$ \\
\hline 0.99 & 3.5 & 2.7 & 0.8 & 1 & 0.1 & 0.9997 & -0.1 & 0.9999 & -0.1 & 0.9999 \\
\hline 0.66 & 3.3 & 2.5 & 0.8 & 1 & 0.2 & 0.9999 & -0.2 & 0.9997 & 0 & 1.0 \\
\hline 0.33 & 3.4 & 2.6 & 0.8 & 1 & 0 & 1.0 & -0.3 & 0.998 & 0.1 & 0.9999 \\
\hline 0.09 & 3.9 & 3.1 & 0.8 & 1 & -0.2 & 0.999 & -0.7 & 0.988 & 0.8 & 0.991 \\
\hline
\end{tabular}

\footnotetext{
${ }^{18}$ Benigno (2001) shows that a weighted average of the two inflation rates (in an optimal currency area) should be targeted, given equal nominal rigidities across the two sectors.

${ }^{19}$ Note also that the results are not (qualitatively) affected by whether an interest rate smoothing-objective is included in either of the two social loss functions.
} 
Table 5b: Social loss $\left(L^{D}=\operatorname{var}\left(\pi^{D}\right)+\lambda^{S} \operatorname{var}(y)\right)$, and optimized reaction coefficients, policy reaction to domestic inflation $\left(\pi_{t}^{D}\right)$

\begin{tabular}{|c|c|c|c|c|c|c|c|c|c|c|}
\hline \multirow{2}{*}{$\begin{array}{l}\text { Pass- } \\
\text { through }\end{array}$} & \multirow[b]{2}{*}{$\hat{b}_{\pi}$} & \multicolumn{3}{|c|}{ equation (7a) } & \multicolumn{2}{|c|}{ equation (7b) } & \multicolumn{2}{|c|}{ equation (7c) } & \multicolumn{2}{|c|}{ equation $(7 d)$} \\
\hline & & $\hat{b}_{y}$ & $\hat{\rho}$ & $L_{d}^{D} / L^{D}$ & $\hat{b}_{\Delta e}$ & Rel. $L_{d}^{D}$ & $\hat{b}_{(p m-p d)}$ & Rel. $L_{d}^{D}$ & $\hat{b}_{\left(p^{*}+e-p\right)}$ & Rel. $L_{d}^{D}$ \\
\hline 0.99 & 3.5 & 2.8 & 0.8 & 1.01 & 0.2 & 0.998 & 0.1 & 0.9999 & 0.1 & 0.9999 \\
\hline 0.66 & 3.3 & 2.6 & 0.8 & 1.009 & 0.2 & 0.999 & -0.1 & 0.9999 & 0.3 & 0.986 \\
\hline 0.33 & 5.5 & 4.6 & 0.9 & 0.9994 & 0.2 & 0.9996 & -0.4 & 0.999 & 0.5 & 0.999 \\
\hline 0.09 & 3.4 & 2.8 & 0.8 & 1.023 & 0 & 1.0 & -0.7 & 0.984 & 1.0 & 0.983 \\
\hline
\end{tabular}

Note: $L_{d}^{D} / L^{D}$ denotes the relative loss compared to delegating equation (7a) based on CPI inflation. Rel. $L_{d}^{D}$ represents the relative loss between the respective exchange-rate augmented rule and equation (7a), based on domestic inflation (i.e. the loss reduction from exchange rate stabilization under domestic inflation targeting). $b_{\pi}$, $b_{y}, \rho$ are optimized separately in order to reflect the marginal advantage of incorporating an exchange-rate term.

\section{Robustness issues}

Does the exchange rate have an explicit role (in the monetary policy conduct) if the economy becomes more open in terms of larger import and export shares? In this case, foreign disturbances have a larger impact on the domestic economy, and one might think that this should also affect the policy rule. Nonetheless, adding an exchange-rate term to the (re)optimized policy rule does not notably improve welfare. The reaction coefficients on inflation and output do, however, appear to be increasing in the degree of openness (see Table A2 in the Appendix).

If the persistence in the risk premium shock increases, it induces larger and more prolonged exchange rate movements, which thus have a larger effect on the economy. Consequently, there are reasons for a more aggressive and long-lasting policy reaction. However, neither in this case do the exchange-rate augmented rules imply any greater welfare improvements compared to the fully optimized policy rule. Note though that the other reactions on inflation and output compensate for the lack of an explicit exchange-rate term, so that the resulting policy rule is anyhow a lot more vigorous (see Table A3 in the Appendix).

The same applies if the relative variances of the foreign disturbances are larger. For example, increasing the relative importance of risk premium disturbances does not change the main results. In this case, the welfare improvement of adding an exchange-rate term to the standard 
Taylor rule is somewhat larger, but the exchange-rate augmented rules do not outperform the fully optimized rule (see Table A4 in the Appendix).

\section{Conclusions}

The performance of various open-economy policy rules is analyzed within a forward-looking aggregate supply-aggregate demand model, adjusted for incomplete exchange rate pass-through. The results show that policy rules with direct exchange rate reactions do not outperform the optimized Taylor rule. Neither nominal, nor real, exchange rate responses do enhance the stabilization of the economy. There are no sizeable social welfare improvements from using exchange-rate augmented rules, irrespective of the degree of pass-through, given optimized reactions to inflation and output.

However, an indirect, or implicit, exchange rate response is welfare improving. A policy rule responding to CPI inflation does better in social welfare terms than a rule based on domestic inflation, in all pass-through cases. This inherent exchange rate reaction, included in the CPI inflation response, appears to be one of the reasons why a direct exchange rate response is redundant. Note also that this result is not contingent upon social preferences for either CPI inflation stabilization or domestic inflation stabilization. Consequently, in this model, it is better for the policy maker to respond to CPI inflation, since this induces lower exchange rate volatility, which, in turn, also reduces domestic inflation variability.

The only case where social welfare improves from the inclusion of a direct exchange rate reaction occurs when a real exchange rate response is added to the non-optimized Taylor rule (i.e. with standard reaction coefficients on inflation, output, and the lagged interest rate; 1.5, 0.5, and 0.8 , respectively). Adding a real exchange rate response to the Taylor rule makes the interest rate adjustment somewhat more aggressive. This reduces the sub-optimality of the resulting overall policy reaction, which consequently enhances welfare. The exchange rate reaction, as well as the welfare gain, is increasing in the degree of pass-through. 


\section{Appendix}

\section{A.1 State-space representation, model dynamics, and asymptotic variances}

To formulate the model (i.e. equations (1)-(6)) in state-space form, the following components, shock processes, and identities are used:

(A1a) $\pi_{t}^{M}=\beta \mathrm{E}_{\mathrm{t}} \pi_{t+1}^{M}+\frac{\alpha_{p}}{\kappa_{M}}\left(p_{t}^{*}+e_{t}-p_{t}^{M}\right)$,

(A1b) $\pi_{t}^{D}=\beta \mathrm{E}_{\mathrm{t}} \pi_{t+1}^{D}+\frac{1}{\left(1-\kappa_{M}\right)}\left(\alpha_{y} y_{t}+\alpha_{q}\left(p_{t}^{M}-p_{t}^{D}\right)+\varepsilon_{t}^{\pi}\right)$,

(A2a) $\varepsilon_{t+1}^{\pi}=\tau_{\pi} \varepsilon_{t}^{\pi}+v_{t+1}^{\pi}$,

(A2b) $\varepsilon_{t+1}^{y}=\tau_{y} \varepsilon_{t}^{y}+v_{t+1}^{y}$,

(A2c) $\varepsilon_{t+1}^{\phi}=\tau_{\phi} \varepsilon_{t}^{\phi}+v_{t+1}^{\phi}$,

(A3a) $\quad\left(p_{t}^{M}-p_{t}^{D}\right)=\left(p_{t-1}^{M}-p_{t-1}^{D}\right)+\pi_{t}^{M}-\pi_{t}^{D}$,

(A3b) $\quad\left(p_{t}^{*}+e_{t}-p_{t}^{M}\right)=\left(p_{t-1}^{*}+e_{t-1}-p_{t-1}^{M}\right)+\pi_{t}^{*}+\Delta e_{t}-\pi_{t}^{M}$.

The state-space representation is

$$
\begin{aligned}
& \tilde{A}_{0}\left[\begin{array}{c}
x_{1, t+1} \\
\mathrm{E}_{\mathrm{t}} x_{2, t+1}
\end{array}\right]=\tilde{A}\left[\begin{array}{l}
x_{1, t} \\
x_{2, t}
\end{array}\right]+\tilde{B} i_{t}+\widetilde{v}_{t+1} \\
& x_{1, t}=\left[\begin{array}{llllllllll}
i_{t-1} & y_{t}^{*} & i_{t}^{*} & \pi_{t}^{*} & \varepsilon_{t}^{\pi} & \varepsilon_{t}^{\phi} & \varepsilon_{t}^{y} & \left(p_{t-1}^{M}-p_{t-1}^{D}\right) & \left(p_{t-1}^{*}+e_{t-1}-p_{t-1}^{M}\right)
\end{array}\right]^{\prime} \text {, } \\
& x_{2, t}=\left[\begin{array}{llll}
y_{t} & \pi_{t}^{D} & \pi_{t}^{M} & \Delta e_{t}
\end{array}\right]^{\prime} \text {, } \\
& \widetilde{v}_{t+1}=\left[\begin{array}{lllllllllllll}
0 & u_{t+1}^{y^{*}} & u_{t+1}^{i^{*}} & u_{t+1}^{\pi^{*}} & u_{t+1}^{\pi} & u_{t+1}^{\phi} & u_{t+1}^{y} & 0 & 0 & 0 & 0 & 0 & 0
\end{array}\right]^{\prime},
\end{aligned}
$$

where $x_{1, t}$ is a $9 \times 1$ vector of predetermined state variables, $x_{2, t}$ is a $4 \times 1$ vector of forward-looking variables, and $\widetilde{v}_{t+1}$ is a $13 \times 1$ vector of disturbances, 


$$
\begin{aligned}
& \tilde{A}_{0}=\left[\begin{array}{ccccccccccccr}
1 & 0 & 0 & 0 & 0 & 0 & 0 & 0 & 0 & 0 & 0 & 0 & 0 \\
0 & 1 & 0 & 0 & 0 & 0 & 0 & 0 & 0 & 0 & 0 & 0 & 0 \\
0 & -b_{y}^{*}\left(1-\rho_{i}^{*}\right) & 1 & -b_{\pi}^{*}\left(1-\rho_{i}^{*}\right) & 0 & 0 & 0 & 0 & 0 & 0 & 0 & 0 & 0 \\
0 & 0 & 0 & 1 & 0 & 0 & 0 & 0 & 0 & 0 & 0 & 0 & 0 \\
0 & 0 & 0 & 0 & 1 & 0 & 0 & 0 & 0 & 0 & 0 & 0 & 0 \\
0 & 0 & 0 & 0 & 0 & 1 & 0 & 0 & 0 & 0 & 0 & 0 & 0 \\
0 & 0 & 0 & 0 & 0 & 0 & 1 & 0 & 0 & 0 & 0 & 0 & 0 \\
0 & 0 & 0 & 0 & 0 & 0 & 0 & 1 & 0 & 0 & 0 & 0 & 0 \\
0 & 0 & 0 & 0 & 0 & 0 & 0 & 0 & 1 & 0 & 0 & 0 & 0 \\
0 & 0 & 0 & 0 & 0 & 0 & 0 & 0 & 0 & 1 & \left(1-\kappa_{M}\right) \beta_{i}+\beta_{q}+\beta_{e} & \kappa_{M} \beta_{i}-\beta_{q} & 0 \\
0 & 0 & 0 & 0 & 0 & 0 & 0 & \frac{\kappa_{a q}}{\left(1-\kappa_{M}\right)} & 0 & 0 & \beta_{\pi} & 0 & 0 \\
0 & 0 & 0 & 0 & 0 & 0 & 0 & 0 & \frac{a_{p}}{\kappa_{M}} & 0 & 0 & \beta_{\pi} & 0 \\
0 & 0 & 0 & 0 & 0 & 0 & 0 & 0 & 0 & 0 & 0 & 0 & 1
\end{array}\right], \\
& \tilde{A}=\left[\begin{array}{ccccccccccccc}
0 & 0 & 0 & 0 & 0 & 0 & 0 & 0 & 0 & 0 & 0 & 0 & 0 \\
0 & \rho_{y}^{*} & 0 & 0 & 0 & 0 & 0 & 0 & 0 & 0 & 0 & 0 & 0 \\
0 & 0 & \rho_{i}^{*} & 0 & 0 & 0 & 0 & 0 & 0 & 0 & 0 & 0 & 0 \\
0 & 0 & 0 & \rho_{\pi}^{*} & 0 & 0 & 0 & 0 & 0 & 0 & 0 & 0 & 0 \\
0 & 0 & 0 & 0 & \tau_{\pi} & 0 & 0 & 0 & 0 & 0 & 0 & 0 & 0 \\
0 & 0 & 0 & 0 & 0 & \tau_{\phi} & 0 & 0 & 0 & 0 & 0 & 0 & 0 \\
0 & 0 & 0 & 0 & 0 & 0 & \tau_{y} & 0 & 0 & 0 & 0 & 0 & 0 \\
0 & 0 & 0 & 0 & 0 & 0 & 0 & 1 & 0 & 0 & -1 & 1 & 0 \\
0 & 0 & 0 & 1 & 0 & 0 & 0 & 0 & 1 & 0 & 0 & -1 & 1 \\
0 & -\beta_{y}^{*}\left(1-\rho_{y}^{*}\right) & -\beta_{e} & \rho_{\pi}^{*} \beta_{e} & 0 & -\beta_{e} & -1 & 0 & 0 & 1 & 0 & 0 & 0 \\
0 & 0 & 0 & 0 & -1 & 0 & 0 & 0 & 0 & -\frac{a_{y}}{\left(1-\kappa_{M}\right)} & 1 & 0 & 0 \\
0 & 0 & 0 & 0 & 0 & 0 & 0 & 0 & 0 & 0 & 0 & 1 & 0 \\
0 & 0 & -1 & 0 & 0 & -1 & 0 & 0 & 0 & 0 & 0 & 0 & 0
\end{array}\right], \\
& \tilde{B}=\left[\begin{array}{lllllllllllll}
1 & 0 & 0 & 0 & 0 & 0 & 0 & 0 & 0 & \left(\beta_{i}+\beta_{e}\right) & 0 & 0 & 1
\end{array}\right]^{\prime} .
\end{aligned}
$$

Premultiplying (A4) with $\tilde{A}_{0}^{-1}$, and inserting the monetary policy reaction, $i_{t}=-F\left[\begin{array}{ll}x_{1, t} & x_{2, t}\end{array}\right]^{\prime}$, yields

$$
\left[\begin{array}{c}
x_{1, t+1} \\
\mathrm{E}_{\mathrm{t}} x_{2, t+1}
\end{array}\right]=(A-B F)\left[\begin{array}{c}
x_{1, t} \\
x_{2, t}
\end{array}\right]+\left[\begin{array}{c}
v_{1, t+1} \\
0_{4 \times 1}
\end{array}\right],
$$

where $A=\tilde{A}_{0}^{-1} \tilde{A}, \quad B=\tilde{A}_{0}^{-1} \tilde{B}$, and $\left[\begin{array}{cc}v_{1, t+1} & 0_{4 \times 1}\end{array}\right]^{\prime}=\tilde{A}_{0}^{-1} \tilde{v}_{t+1}$. Provided that the policy rule, $F$, implies a unique equilibrium, the dynamics of the model is given by

(A6a) $x_{1, t+1}=M^{s} x_{1, t}+v_{1, t+1}$,

(A6b) $x_{2, t+1}=H^{s} x_{1, t+1}$, 
where $M^{s}$ and $H^{s}$ can be found using a Schur decomposition of $(A-B F)$.

Given the system's dynamics in equation (A6), the variance-covariance matrix of the predetermined variables results from

(A7a) $\sum_{x 1}=M^{s} \sum_{x 1} M^{s^{\prime}}+\sum_{v 1}$,

(A7b) $\operatorname{vec}\left(\sum_{x 1}\right)=\left[I_{n 1^{2}}-\left(M^{s} \otimes M^{s}\right)\right]^{-1} \operatorname{vec}\left(\sum_{v 1}\right)$,

where the unconditional variance-covariance matrix of the disturbance vector, $v_{t+1}$, is given by $\Sigma_{v}=\left(\begin{array}{ll}\Sigma_{v 1} & 0_{9 \times 4}\end{array}\right)$, where $\Sigma_{v 1}$ is defined as

$$
\Sigma_{v 1}=\left[\begin{array}{ccccccccc}
0 & 0 & 0 & 0 & 0 & 0 & 0 & 0 & 0 \\
0 & \sigma_{y^{*}}^{2} & \left(1-\rho_{i}^{*}\right) b_{y}^{*} \sigma_{y^{*}}^{2} & 0 & 0 & 0 & 0 & 0 & 0 \\
0 & \left(1-\rho_{i}^{*}\right) b_{y}^{*} \sigma_{y^{*}}^{2} & \sigma_{i^{*}}^{2}+\left(1-\rho_{i}^{*}\right)^{2}\left(b_{\pi}^{* 2} \sigma_{\pi^{*}}^{2}+b_{y}^{* 2} \sigma_{y^{*}}^{2}\right) & \left(1-\rho_{i}^{*}\right) b_{\pi}^{*} \sigma_{\pi^{*}}^{2} & 0 & 0 & 0 & 0 & 0 \\
0 & 0 & \left(1-\rho_{i}^{*}\right) b_{\pi}^{*} \sigma_{\pi^{*}}^{2} & \sigma_{\pi^{*}}^{2} & 0 & 0 & 0 & 0 & 0 \\
0 & 0 & 0 & 0 & \sigma_{\pi}^{2} & 0 & 0 & 0 & 0 \\
0 & 0 & 0 & 0 & 0 & \sigma_{\phi}^{2} & 0 & 0 & 0 \\
0 & 0 & 0 & 0 & 0 & 0 & \sigma_{y}^{2} & 0 & 0 \\
0 & 0 & 0 & 0 & 0 & 0 & 0 & 0 & 0 \\
0 & 0 & 0 & 0 & 0 & 0 & 0 & 0 & 0
\end{array}\right],
$$

The variables of interest $\left(z_{t}\right)$ can be expressed as a function of the predetermined variables,

$$
\begin{aligned}
z_{t+1} & =T_{x} x_{t+1}+T_{i} i_{t+1} \\
& =\left[\begin{array}{ll}
T_{x 1} & T_{x 2}
\end{array}\right]\left[\begin{array}{l}
x_{1, t+1} \\
x_{2, t+1}
\end{array}\right]+T_{i} i_{t+1} \\
& =\left[\begin{array}{ll}
T_{x 1} & T_{x 2}
\end{array}\right]\left[\begin{array}{c}
x_{1, t+1} \\
H^{s} x_{1, t+1}
\end{array}\right]-T_{i}\left[\begin{array}{ll}
F_{1} & F_{2}
\end{array}\right]\left[\begin{array}{c}
x_{1, t+1} \\
H^{s} x_{1, t+1}
\end{array}\right] \\
& =T^{s} x_{1, t+1},
\end{aligned}
$$

yielding the following variance-covariance matrix for $\left(z_{t}\right)$ :

(A12) $\quad \sum_{z}=T^{s} \sum_{x 1} T^{s^{\prime}}$. 
Table A1a: Unconditional variances and social loss, using standard reaction coefficients on $\left(b_{\pi}, b_{y}, \rho\right)$

\begin{tabular}{|c|c|c|c|c|c|c|c|}
\hline \multirow[b]{2}{*}{ Pass-through } & \multicolumn{7}{|c|}{$b_{\pi}=1.5, b_{y}=0.5, \rho=0.8$} \\
\hline & $\operatorname{var}(\pi)$ & $\operatorname{var}(y)$ & $\operatorname{var}\left(p^{M}-p^{D}\right)$ & $\operatorname{var}(\Delta \mathrm{e})$ & $\operatorname{var}(i)$ & $\operatorname{var}\left(\pi^{D}\right)$ & $\operatorname{var}\left(\pi^{M}\right)$ \\
\hline 0.99 & 9.037 & 27.180 & 7.162 & 12.191 & 4.325 & 8.759 & 12.061 \\
\hline 0.66 & 8.533 & 25.576 & 5.984 & 12.930 & 4.10 & 8.67 & 9.259 \\
\hline 0.33 & 7.938 & 24.756 & 5.865 & 13.925 & 3.764 & 8.448 & 7.308 \\
\hline 0.09 & 6.688 & 24.678 & 11.315 & 15.575 & 3.106 & 7.754 & 4.979 \\
\hline
\end{tabular}

Table A1b: Unconditional variances and social loss, using optimized reaction coefficients

\begin{tabular}{|l|c|c|c|c|c|c|c|}
\hline \hline & \multicolumn{7}{c|}{ optimized reactions; see Table 3a } \\
& \multicolumn{7}{|c|}{ equation $(7 \mathrm{a}) ; i_{t}=(1-\rho)\left(b_{\pi} \pi_{t}+b_{y} y_{t}\right)+\rho i_{t-1}$} \\
& \multicolumn{8}{|c|}{$\operatorname{var}(y)$} & $\operatorname{var}\left(p^{M}-p^{D}\right)$ & $\operatorname{var}(\Delta \mathrm{e})$ & $\operatorname{var}(i)$ & $\operatorname{var}\left(\pi^{D}\right)$ & $\operatorname{var}\left(\pi^{M}\right)$ \\
\hline \multirow{2}{*}{ Pass-through } & $\operatorname{var}(\pi)$ & & & & & & \\
0.99 & 11.852 & 11.443 & 5.426 & 12.853 & 8.458 & 12.034 & 12.726 \\
0.66 & 11.555 & 11.461 & 5.04 & 13.398 & 8.031 & 11.902 & 11.542 \\
0.33 & 11.36 & 10.831 & 5.314 & 14.501 & 7.754 & 11.948 & 10.539 \\
0.09 & 10.508 & 9.113 & 12.37 & 16.295 & 7.735 & 11.708 & 8.487 \\
\hline \hline
\end{tabular}

Table A1c: Unconditional variances and social loss, responding to domestic inflation $\left(\pi_{t}^{D}\right)$

\begin{tabular}{|c|c|c|c|c|c|c|c|}
\hline \multirow[b]{3}{*}{ Pass-through } & \multicolumn{7}{|c|}{ optimized reactions; see Table 4} \\
\hline & \multicolumn{7}{|c|}{ equation (7a); $i_{t}=(1-\rho)\left(b_{\pi} \pi_{t}^{D}+b_{y} y_{t}\right)+\rho i_{t-1}$} \\
\hline & $\operatorname{var}(\pi)$ & $\operatorname{var}(y)$ & $\operatorname{var}\left(p^{M}-p^{D}\right)$ & $\operatorname{var}(\Delta \mathrm{e})$ & $\operatorname{var}(i)$ & $\operatorname{var}\left(\pi^{D}\right)$ & $\operatorname{var}\left(\pi^{M}\right)$ \\
\hline 0.99 & 12.214 & 11.164 & 5.57 & 13.487 & 8.747 & 12.363 & 13.348 \\
\hline 0.66 & 11.885 & 11.147 & 5.091 & 14.058 & 8.257 & 12.213 & 11.976 \\
\hline 0.33 & 11.143 & 11.266 & 5.355 & 14.784 & 7.142 & 11.722 & 10.350 \\
\hline 0.09 & 11.042 & 8.784 & 12.473 & 17.128 & 8.123 & 12.257 & 8.986 \\
\hline
\end{tabular}


Table A2: Social loss $\left(L^{S}\right)$ and optimized reaction coefficients, greater openness

\begin{tabular}{|l|cccc|cc|cc|cc|}
\hline \hline \multirow{2}{*}{$\begin{array}{l}\text { Pass- } \\
\text { through }\end{array}$} & \multicolumn{4}{|c}{ equation (7a) } & \multicolumn{9}{c|}{ equation (7b) } & \multicolumn{2}{c|}{ equation (7c) } & \multicolumn{2}{c|}{ equation (7d) } \\
& $\hat{b}_{\pi}$ & $\hat{b}_{y}$ & $\hat{\rho}$ & $L^{D}$ & $\hat{b}_{\Delta e}$ & Rel. $L^{D}$ & $\hat{b}_{(p m-p d)}$ & Rel. $L^{D}$ & $\hat{b}_{\left(p^{*}+e-p\right)}$ & Rel. $L^{D}$ \\
\hline & & & & & & & & & & \\
0.99 & 4.5 & 3.6 & 0.8 & 1 & 0.1 & 0.9999 & 0.1 & 0.9999 & 0.3 & 0.9999 \\
0.66 & 4.4 & 3.6 & 0.8 & 1 & 0.1 & 0.9999 & -0.2 & 0.9999 & 0.7 & 0.9997 \\
0.33 & 4.6 & 3.9 & 0.8 & 1 & -0.1 & 0.9999 & -0.5 & 0.999 & 1.3 & 0.998 \\
0.09 & 3.9 & 3.7 & 0.7 & 1 & -0.3 & 0.997 & -0.7 & 0.987 & 1.0 & 0.984 \\
\hline \hline
\end{tabular}

Note: The size of the import and export shares, and the share of imported inputs are doubled (i.e. $60 \%$ and 20\%, respectively, in contrast to the benchmark case; $30 \%$ and $10 \%) . b_{\pi}, b_{y}, \rho$ are optimized separately in order to reflect the marginal advantage of incorporating an exchange-rate term.

Table A3: Social loss $\left(L^{S}\right)$ and optimized reaction coefficients, larger risk premium persistence

\begin{tabular}{|c|c|c|c|c|c|c|c|c|c|c|}
\hline \multirow{2}{*}{$\begin{array}{l}\text { Pass- } \\
\text { through }\end{array}$} & \multicolumn{4}{|c|}{ equation (7a) } & \multicolumn{2}{|c|}{ equation (7b) } & \multicolumn{2}{|c|}{ equation $(7 c)$} & \multicolumn{2}{|c|}{ equation (7d) } \\
\hline & $\hat{b}_{\pi}$ & $\hat{b}_{y}$ & $\hat{\rho}$ & $L^{D}$ & $\hat{b}_{\Delta e}$ & Rel. $L^{D}$ & $\hat{b}_{(p m-p d)}$ & Rel. $L^{D}$ & $\hat{b}_{\left(p^{*}+e-p\right)}$ & Rel. $L^{D}$ \\
\hline 0.99 & 7.5 & 5.9 & 0.9 & 1 & 0.4 & 0.999 & 0.9 & 0.982 & 1.2 & 0.982 \\
\hline 0.66 & 6.7 & 5.2 & 0.9 & 1 & 0.3 & 0.999 & 0.7 & 0.981 & 1.1 & 0.98 \\
\hline 0.33 & 6.5 & 5.1 & 0.9 & 1 & 0.2 & 0.9998 & 0.7 & 0.982 & 1.0 & 0.981 \\
\hline 0.09 & 7.5 & 6.6 & 0.9 & 1 & -0.1 & 0.9999 & 0.4 & 0.996 & 1.1 & 0.977 \\
\hline
\end{tabular}

Note: The risk premium persistence is $\tau_{\phi}=0.95 . b_{\pi}, b_{y}, \rho$ are optimized separately in order to reflect the marginal advantage of incorporating an exchange-rate term.

Table A4: Social loss $\left(L^{S}\right)$ and optimized reaction coefficients, larger risk premium variance

\begin{tabular}{|l|cccc|cc|cc|cc|}
\hline \hline \multirow{2}{*}{$\begin{array}{l}\text { Pass- } \\
\text { through }\end{array}$} & \multicolumn{4}{|c}{ equation (7a) } & \multicolumn{1}{c|}{ equation (7b) } & \multicolumn{2}{c|}{ equation (7c) } & \multicolumn{2}{c|}{ equation (7d) } \\
& $\hat{b}_{\pi}$ & $\hat{b}_{y}$ & $\hat{\rho}$ & $L^{D}$ & $\hat{b}_{\Delta e}$ & Rel. $L^{D}$ & $\hat{b}_{(p m-p d)}$ & Rel. $L^{D}$ & $\hat{b}_{\left(p^{*}+e-p\right)}$ & Rel. $L^{D}$ \\
\hline & & & & & & & & & & \\
0.99 & 7.3 & 6.8 & 0.8 & 1 & 0.5 & 0.998 & 1.1 & 0.996 & 1.5 & 0.996 \\
0.66 & 6.8 & 6.3 & 0.8 & 1 & 0.4 & 0.999 & 0.8 & 0.998 & 1.5 & 0.995 \\
0.33 & 6.5 & 6.1 & 0.8 & 1 & 0.3 & 0.999 & 0 & 1.0 & 1.7 & 0.991 \\
0.09 & 7.0 & 7.2 & 0.8 & 1 & -0.1 & 1.0 & -1.8 & 0.981 & 2.6 & 0.9 \\
\hline \hline
\end{tabular}

Note: The risk premium variance is five times larger than in the basecase parameterization; $\sigma_{\phi}^{2}=2.0 . b_{\pi}, b_{y}, \rho$ are optimized separately in order to reflect the marginal advantage of incorporating an exchange-rate term. 
Figure 1: Social loss under varying degrees of exchange rate reactions added to the Taylor rule

a) Pass-Through $=0.99$

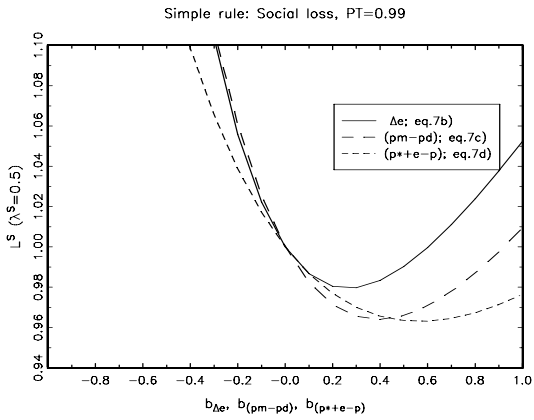

c) Pass-Through $=0.33$

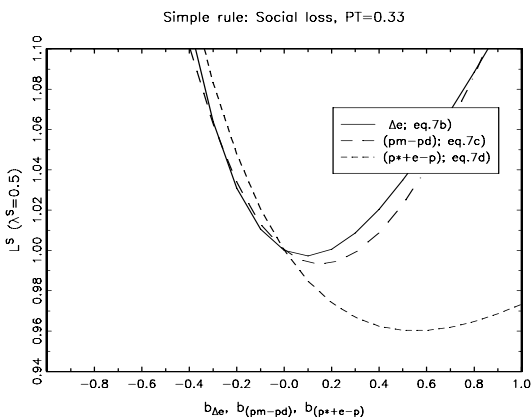

b) Pass-Through $=0.66$

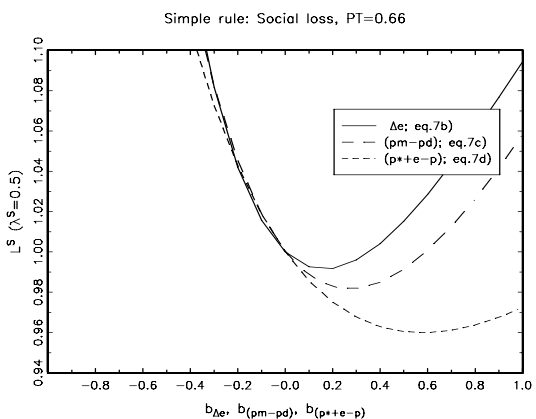

d) Pass-Through $=0.09$

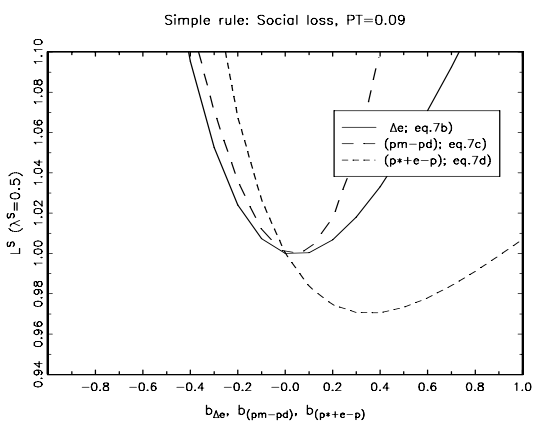

Note: Relative social loss compared to the social loss under the Taylor rule without the exchange rate.

Truncated y-axis. 
Figure 2: Social loss under varying degrees of exchange rate reactions added to the optimized rule

a) Pass-Through $=0.99$

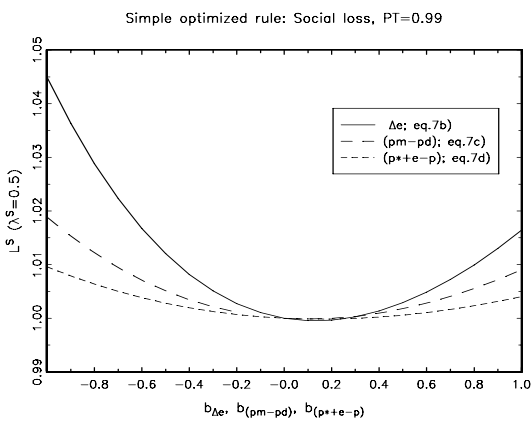

c) Pass-Through $=0.33$

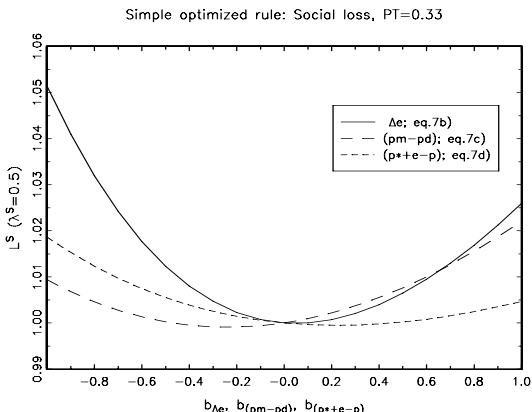

b) Pass-Through $=0.66$

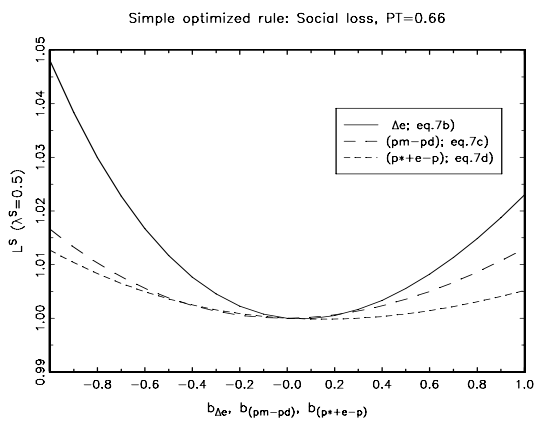

d) Pass-Through $=0.09$

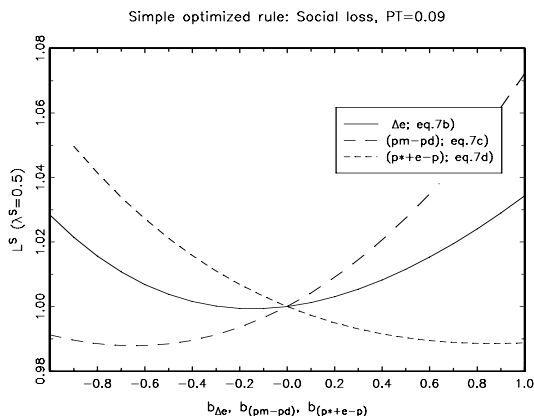

Note: Relative social loss compared to the social loss under the optimized rule without the exchange rate. 
Figure 3: Impulse responses for the case with full pass-through (99\%; solid) and with incomplete pass-through (33\%; dashed), using optimized rules
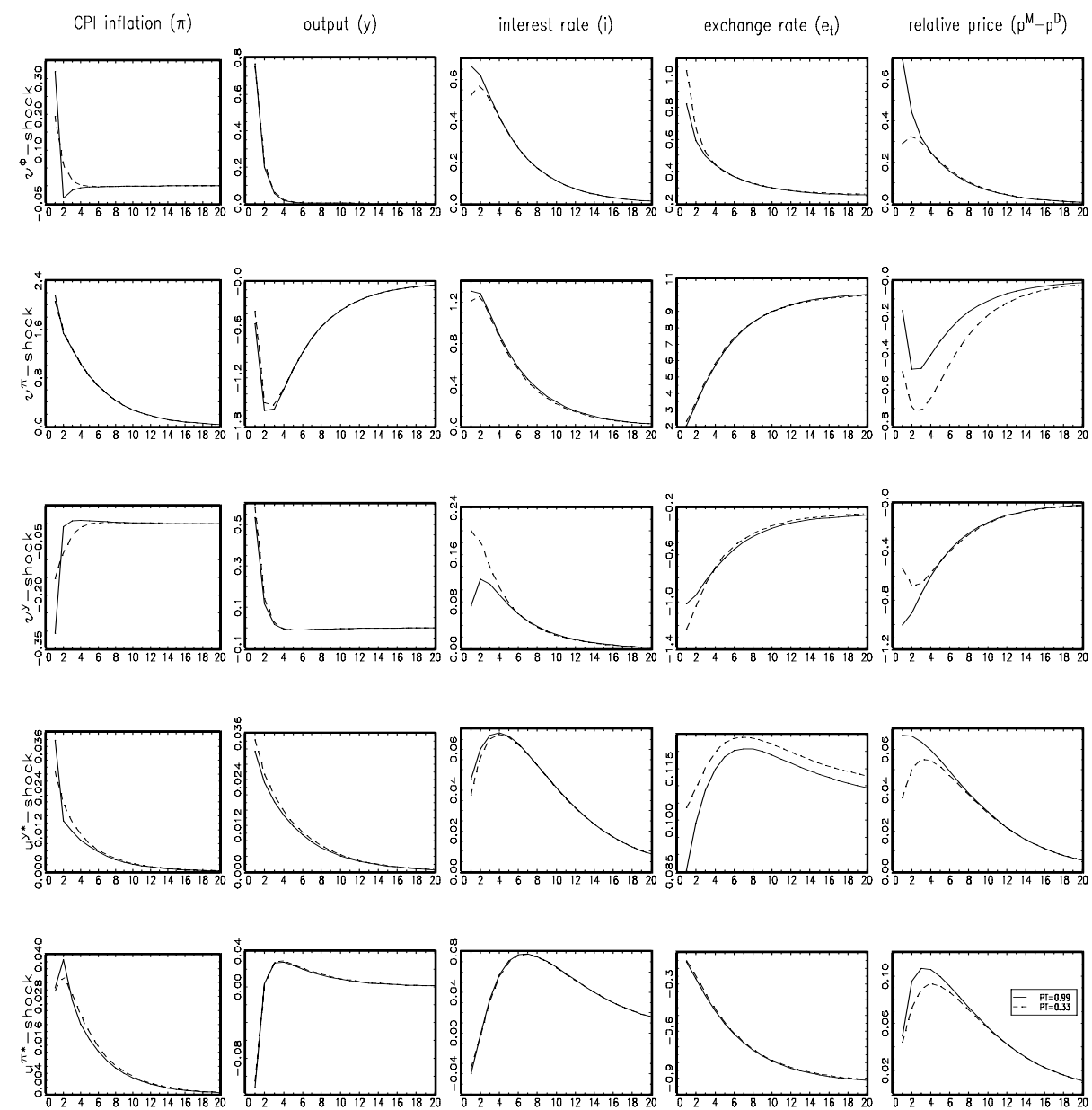
Figure 4: Domestic inflation-output variance trade-off, CPI inflation based rule vs. domestic inflation based rule

a) Pass-Through $=0.99$

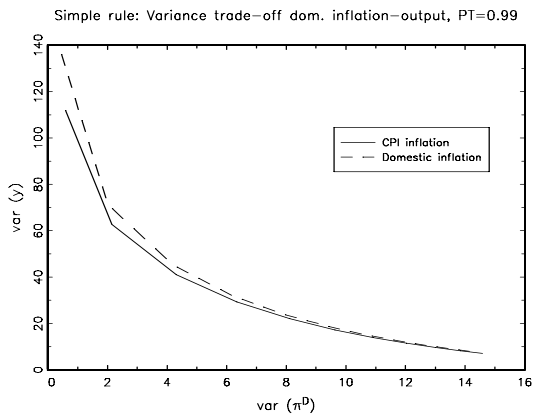

c) Pass-Through $=0.33$

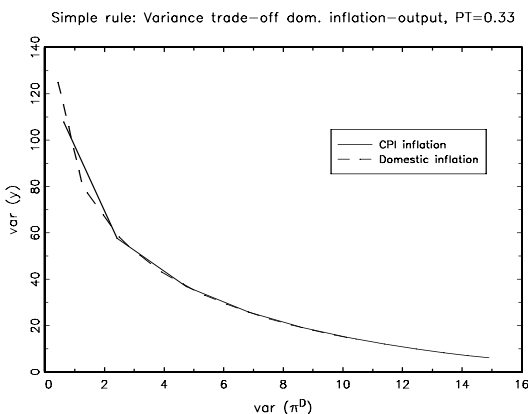

b) Pass-Through $=0.66$

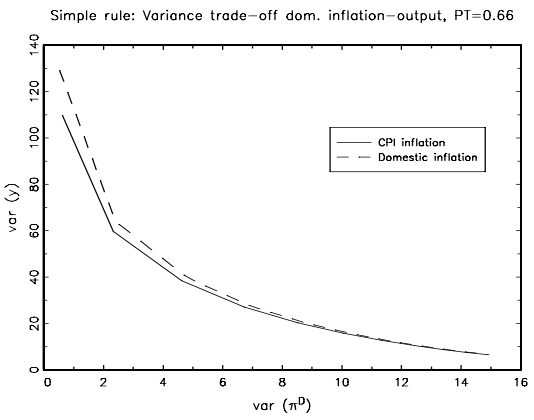

d) Pass-Through $=0.09$

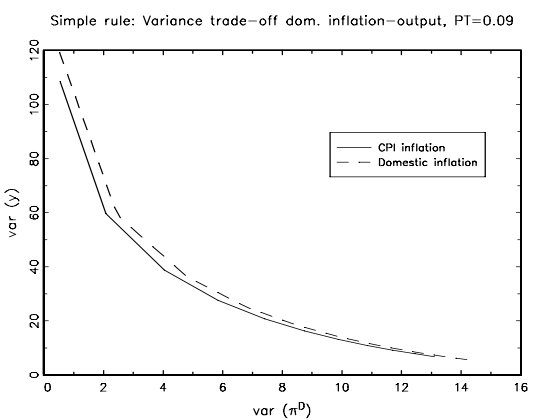

Note: Optimized policy rules, varying the degree of output response between 0-4, step 0.4. For inflation and interest rate reactions, see Tables $3 \mathrm{a}$ and 4 , respectively. 


\section{References}

Adolfson, M. (2001a), "Monetary Policy with Incomplete Exchange Rate Pass-Through", Working Paper in Economics and Finance, No. 476, Stockholm School of Economics.

Adolfson, M. (2001b), “Optimal Monetary Policy Delegation under Incomplete Exchange Rate Pass-Through", Working Paper in Economics and Finance, No. 477, Stockholm School of Economics.

Adolfson, M. (1997), "Exchange Rate Pass-Through to Swedish Import Prices", Finnish Economic Papers, Vol. 10, No. 2, 81-98.

Ball, L. (2000), "Policy Rules and External Shocks”, NBER Working Paper, No. 7910.

Ball, L. (1999), "Policy Rules for Open Economies", in Taylor, J. (ed.), Monetary Policy Rules, University of Chicago Press.

Batini, N., Harrison, R. and Millard, S. P. (2001), "Monetary Policy Rules for an Open Economy", manuscript, Bank of England.

Benigno, P. (2001), "Optimal Monetary Policy in a Currency Area”, manuscript, New York University.

Cecchetti, S., Genberg, H., Lipsky, J. and Wadhwani, S. (2000), “Asset Prices and Central Bank Policy", Geneva Reports on the World Economy, No.2, ICMB/CEPR.

Clarida, R., Galí, J. and Gertler, M. (2000), "Monetary Policy Rules and Macroeconomic Stability: Evidence and Some Theory", Quarterly Journal of Economics, Vol. 115, No. 1, 147180.

Clarida, R., Galí, J. and Gertler, M. (1998), "Monetary Policy Rules in Practice: Some International Evidence", European Economic Review, Vol. 42, No. 6, 1033-1067.

Gerlach, S. and Schnabel, G. (2000), "The Taylor Rule and Interest Rates in the EMU Area”, Economics Letters, Vol. 67, No. 2, 165-171. 
Leitemo, K. and Røisland, Ø. (2000), “The Choice of Monetary Policy Regime for Small Open Economies", Working Paper No. 5/2000, Norges Bank.

Leitemo, K. and Söderström, U. (2001), "Simple Monetary Policy Rules and Exchange Rate Uncertainty", Sveriges Riksbank Working Paper, No. 122.

Levin, A., Wieland, V. and Williams, J. C. (1999), "Robustness of Simple Policy Rules under Model Uncertainty", in Taylor, J. (ed.), Monetary Policy Rules, University of Chicago Press.

McCallum, B. and Nelson, E. (1999), "Nominal Income Targeting in an Open-Economy Optimizing Market", Journal of Monetary Economics, Vol. 43, No. 3, 553-578.

Monacelli, T. (1999),"Open Economy Policy Rules under Imperfect Pass-through”, manuscript, Boston College.

Naug, B. and Nymoen, R. (1999), "Pricing to Market in a Small Open Economy", Scandinavian Journal of Economics, Vol. 98, No. 3, 329-350.

Rotemberg, J. (1982), "Monopolistic Price Adjustment and Aggregate Output", Review of Economic Studies, Vol. 49, 517-531.

Rudebusch, G. and Svensson, L.E.O. (1999), "Policy Rules for Inflation Targeting", in Taylor, J. (ed.), Monetary Policy Rules, University of Chicago Press.

Sutherland, A. (2001), "Incomplete Pass-Through and the Welfare Effects of Exchange Rate Variability", manuscript, University of St Andrews.

Söderlind, P. (1999), "Solution and Estimation of RE Macromodels with Optimal Policy", European Economic Review, Vol. 43, 813-823.

Taylor, J. (2001), "The Role of the Exchange Rate in Monetary-Policy Rules", American Economic Review, Vol. 91, No. 2, 263-267. 
Taylor, J. (1993), "Discretion versus Policy Rules in Practice”, Carnegie-Rochester Conference Series on Public Policy, Vol. 39, 195-214.

Weerapana, A. (2000), "The Performance of Simple Monetary Policy Rules in A Large Open Economy", Working Paper, No. 2000-05, Wellesley College.

Woodford, M. (2001), “Inflation Stabilization and Welfare”, NBER Working Paper, No. 8071. 